\title{
Interaction of Z-pins with multiple mode II delaminations in composite laminates
}

\author{
Mehdi Yasaee $^{1 *}$, Galal Mohamed ${ }^{2}$, Stephen R. Hallett ${ }^{2}$ \\ School of Aerospace, Transport and Manufacturing, Cranfield University, Building 83, Cranfield, \\ MK43 OAL, UK \\ Advanced Composites Centre for Innovation and Science (ACCIS), University of Bristol, Queen's \\ Building, University Walk, Bristol, BS8 1TR, UK \\ *m.yasaee@cranfield.ac.uk +44(0)1234754384
}

\begin{abstract}
The application of Z-pinning is a subject of great interest in the field of through-thickness reinforcement (TTR) of composite laminates. To date, the majority of Z-pin characterisation work has been conducted on fracture coupons containing a single embedded delamination, which is often not representative of real failure of reinforced composite structures in service. In this investigation a test procedure to produce two independent Mode II delaminations was developed to analyse their interaction with a region of Z-pin reinforcement.
\end{abstract}

Initially numerical models were used to optimise the chosen configuration. Experimental results show in detail the response of Z-pins to two independent delaminations. These results highlight the ability of the Z-pins to effectively arrest mode II delaminations at multiple levels through the sample thickness. Additionally they provide a much needed data set for validation and verification of Z-pin numerical modelling tools.

\section{Keywords}

Composite, Through thickness reinforcement, Z-pin, multiple delaminations, Mode II, CFRP

\section{Acknowledgements}

The authors would like to acknowledge Rolls-Royce plc for their support of this research through the Composites University Technology Centre (UTC) at the University of Bristol, UK. 


\section{Introduction}

Laminated fibre reinforced (FRP) composites possess poor interlaminar properties and are thus susceptible to delamination from impact, monotonic and cycling loading during service. Delamination damage causes a significant reduction to the stiffness of a composite structure, which may lead to premature catastrophic failure. Through thickness reinforcements (TTR) technologies for composite materials have been shown to improve the resistance of a structure to delaminations. There has thus been a considerable effort to investigate the reinforcement of composites using techniques such as Zpinning, tufting, Z-anchor and 3D woven composites [1]. Of these techniques, the most promising for the reinforcement of pre-preg laminated composites, known as Z-pinning, involves insertion of small diameter fibrous or metallic pins through the thickness of a laminated composite material. This reinforcement process is performed prior to final cure and results in a composite structure with a significantly increased delamination resistance capability [1]. This technique has been successfully used in a number of commercial applications such as Formula 1 cars and the Northrop F18 and Boeing Sikorsky RAH-66 Comanche military aircrafts [2].

The problem of delamination in the absence of reinforcement is well understood, with many experimental studies (e.g. Mode I [3], Mixed Mode I/II [4,5] and Mode II [6,7] tests), numerical studies (e.g. Cohesive Zone Modelling [8-10] and Virtual Crack Closure Technique [11]) and standardised tests (e.g. Mode I Double Cantilever Beam (DCB) Test [12,13], Mode II End Notched Flexure (ENF) [14] and End Loaded Split [15] tests and Mixed Mode Bending (MMB) Test [16]) now being available. For composites reinforced by Z-pins the majority characterisation work has been conducted on specimens containing a single embedded delamination using single pin tests [17-20] or simple fracture tests such as DCB, ENF, ELS, MMB tests [1,21-24,20]. However, in practical engineering applications, composite structures seldom fail through a single delamination. More often, for example when thick composites are subjected to impact loading, multiple delaminations are generated, which is the result of complex damage formation and interactions between matrix cracks, fibre failures and delaminations [25-27]. It has been shown that embedded Z-pins interact with the composite material on a structural level $[28,29]$, in that the embedded length of the pins relative to the crack plane has a direct influence on their suppression of delamination propagation. For this reason, the reinforcement capability of a pin may be affected when more than one delamination is resisted. 
Multiple delaminations without reinforcement have been the subject of extensive studies over the years, especially within areas of in-plane compression and buckling of post-impact damaged composite laminates, with the majority of focus being on development of simplified modelling tools to understand the interaction of such delaminations with one another [30-32]. For a propagating delamination, the presence of other cracks in its vicinity may either amplify, shield or have no influence on its strain energy release rate (SERR) [30,32]. Amplification of the SERR of a crack suggests that it will propagate at a lower global strain energy than if no other defects where present. Shielding of SERR has the opposite effect in that a higher global strain energy is needed to propagate the crack. Zheng et. al. [30] concluded that it is not possible to make general predictions on the amplification or shielding behaviour of a multiple delaminated system and that each individual system of cracks would need to be studied in detail to understand their interactions and response. Andrews et. al. [32] studied the interaction of multiple delaminated beams in bending and made similar conclusions on the complex nature of amplification and shielding of each delamination's SERR. However they did make a prediction that for equally spaced delaminations of equal length, both delaminations would be expected to propagate simultaneously. Further investigations by Andrews and Massabo [33] on the interaction of a propagating delamination in systems with varying thicknesses and embedded imperfections, have shown that the mode ratio of individual delaminations is also significantly affected. It is thus clear that the complications of multiple delaminations have a significant influence on the response of a system to external loading, and that modelling such systems can be quite complex.

The ability of TTR pins to resist the propagation of multiple delamination has not yet been investigated and analysed under controlled experimental conditions. In the work presented here an experimental test configuration for examining the interaction of multiple delaminations with through thickness reinforcement was developed. Initially an unreinforced multiple delamination specimen was simulated using finite element (FE) analysis. Each individual delamination was included in the model using cohesive contacts in the commercial software Abaqus/explicit. This allowed the design of a suitable specimen into which the Z-pin reinforcements were inserted to fully analyse their response. These experimental data will in the future be used to validate Z-pin modelling tools under development [34]. 


\section{Multiple delamination test configuration}

Multiple delaminations are typically observed when a composite structure undergoes out of plane loading. Delaminations formed in this manner are predominantly Mode II dominated. For this reason it was decided to modify the well-established mode II fracture toughness test method of the End Loaded Split (ELS) test [15]. This procedure involves the deflection of a pre-cracked cantilever beam. For the purpose of this investigation the single crack was modified to embed multiple cracks distributed through the thickness of the test specimen. To develop controlled multiple mode II delaminations to interact with the pinned region, this multiple ELS (MELS) specimen was embedded with two different delamination lengths, placed at specific depths through the thickness, similar to those studied analytically by Andrews et al. [32,33].

Four requirements needed to be satisfied when designing the MELS specimen configuration:

1. Resistance of pinned laminates to delamination has been shown to be different for a unidirectional (UD) relative to a non-UD stacking sequence [28]. Thereby the stacking sequence of the specimens for this investigation must be a non-UD type.

2. The stacking sequence of the entire beam, including the delaminated sections, must be symmetric i.e. no extension-bend coupling must be present

3. Delamination must only propagate between two $0^{\circ}$ plies

4. Both delaminations must propagate independently i.e. each delamination initiation has to correspond to a distinguishable critical load

In order to satisfy the first three requirements, the following quasi-isotropic (QI) stacking sequence was adopted: $(0,-45,90,45)_{2 s} / /\left[(0,-45,90,45)_{2 s}\right]_{2} / /(0,-45,90,45)_{2 s}$, where // indicates the insertion of an embedded delamination. For an individual ply thickness of $0.125 \mathrm{~mm}$, this results in a beam with a nominal thickness, $h$ of $8 \mathrm{~mm}$ with the through thickness position of the upper, $a U$ and lower, $a L$ delaminations at $0.25 \mathrm{~h}$ from top and bottom surfaces respectively (Figure 1).

\section{Delamination length behaviour}

\subsubsection{Model Setup}

To satisfy the fourth requirement described in section 2, a detailed FE analysis was carried out to examine the system's behaviour to varying the lengths $a_{U}$ and $a_{L}$. 
An FE model of the MELS setup was created using the explicit version of the ABAQUS FE package.

A $1 \mathrm{~mm}$ wide strip section of the specimen was meshed with 8-noded linear brick elements (C3D8), $1 \mathrm{~mm}$ in size. The two lateral surfaces of the strip section where constrained in the $\mathrm{Y}$ direction with additional constraint in the $\mathrm{X}$ and $\mathrm{Z}$ rotations, effectively replicating plane strain boundary conditions. Bilinear cohesive contact was enabled at the delamination surfaces with non-cohesive contact properties in the normal directional defined as "hard" i.e. no interpenetration allowed and a transverse direction friction coefficient of 0.3 was applied. Load was applied through displacement of the top nodes of the loading edge. The bottom of the beam was fixed in the $\mathrm{z}$ direction at $\mathrm{L}=100 \mathrm{~mm}$ and completely fixed at $\mathrm{L}=110 \mathrm{~mm}$, as shown in Figure 2 . This was done to replicate the experimental test fixture which was found not to completely represent a fully built in end at the end of contact between the grips and the specimen.

The homogenised equivalent material properties applied in the model are provided in Table 1 . These were calculated from simple laminate theory using IM7/8552 prepreg (Hexcel, UK) material properties [35]. The GIC, GIIC properties represent the mode I and mode II fracture toughness, respectively. Mode I fracture toughness was taken from experimental results in [1] and mode II fracture toughness was set for a crack propagating from a $13 \mu \mathrm{m}$ PTFE release film taken from literature [36,37]. This is acceptable since delaminations in the experimental procedure will initiate from the identical release films.

The simulations were run for varying lengths of the upper, $a_{U}$ and lower delaminations, $a_{L}$, from 0 to $80 \mathrm{~mm}$ in $5 \mathrm{~mm}$ increments. Mass scaling was introduced to reduce simulation times. The appropriate mass scaling value used was chosen such that any kinetic energy developed in the model remained below $5 \%$ of the internal energy, ensuring quasi-static conditions were satisfied.

\subsubsection{Results}

Four delamination propagation behaviours were identified which are directly influenced by the upper and lower delamination lengths relative to the length of the beam.

\section{I - Single unstable delamination}

A single unstable delamination may occur for either the upper or lower delamination only, Figure 3a

\section{II - Double simultaneous unstable delaminations}

Both delaminations propagate simultaneously, in an unstable manner, Figure $3 \mathrm{~b}$ 


\section{III - Double simultaneous stable delaminations}

Both delaminations propagate simultaneously however their growth is stable, Figure $3 \mathrm{c}$

\section{IV - Double independent unstable delaminations}

Both delaminations propagate independently, in an unstable manner. This generates the double peak load plot as shown in Figure 3d

In Figure 4, a map is plotted highlighting the four identified regions for various delamination length variations. The dashed line indicates where $a_{U}$ and $a_{L}$ are the same length and when this condition is true, the delamination behaviours fall into Regions II and III. This confirms the behaviour predicted by Andrews et. al. [32] with regards to two equally spaced, equal length delaminations always propagating simultaneously. As can be seen from the map, there are other configurations where similar simultaneous unstable growth can occur. In region III it is expected that the propagation of the shorter delamination will initiate first (Figure 3c). This crack propagates until same length as the longer delamination, before both delaminations propagating simultaneously.

\subsubsection{Amplification and Shielding of strain energy release rates}

Amplification and shielding occurs in systems with multiple delaminations, where the SERR at one of the delamination fronts becomes higher or lower than the SERR of the same delamination in the absence of other cracks. For this investigation this phenomenon can be observed by plotting the normalised strain energy release rate of the upper delamination, $G_{U}$ against the strain energy release rate of the upper delamination without the presence of any other crack, $G_{U o}$ when the same displacement is applied and before any failure has initiated. The strain energy release rate, $G$ was calculated at the crack tip element cohesive interface using the following definition:

$$
G=\int_{0}^{\Delta} \tau(\Delta) d \Delta
$$

Where $\tau$ is the total traction and $\Delta$ is the corresponding local displacement at the cohesive interface. As an example the normalised strain energy release rate for a fixed length upper delamination, $G_{U} / G_{U 0}$, is plotted, as the lower delamination length is increased (shown in Figure 5). When the fixed length of the upper delamination, $a_{U}$, is small (Figure 5a), the length of the lower delamination, $a_{L}$, has little influence on the SERR for lengths less than $a_{U}$. However there is a strong amplification of the SERR of up to 2.5 when $a_{L}$ becomes longer than $a_{U}$. 
As the length $a_{U}$ is increased (Figure $5 \mathrm{~b}$ and c), this amplification effect at longer $a_{L}$ lengths, is decreased. Conversely shielding becomes more apparent when $a_{U}$ is longest and $a_{L}$ is smaller in length than $a_{U}$ (Figure 5c). This implies that multiple short equally spaced cracks in a domain will be far more likely to cause catastrophic sudden delamination growth than multiple longer equally spaced cracks.

A plot of the map of the amplification and shielding effect of the upper and lower delaminations is presented in Figure 6. The amplification of $G_{U}$ can be clearly seen to occur on the domain where $a_{L}>$ $a_{U}$ when observing $G_{U}$. However, when observing $G_{L}$ the amplification on $G_{L}$ occurs on the domain where $a_{U}>a_{L}$. This indicates the region of amplification of one crack would directly correlate with the region of shielding of the other cracks. By combining the two maps using a quadratic formulation:

$$
\frac{\mathrm{G}_{\mathrm{N}}}{\mathrm{G}_{\mathrm{N} 0}}=\sqrt{\left(\frac{G_{U}}{G_{U 0}}\right)^{2}+\left(\frac{G_{L}}{G_{L 0}}\right)^{2}}
$$

shown in Figure 7, it is possible to see that the regions of combined amplification tend to correlate loosely to the unstable double delamination growth, region II, of Figure 4.

\section{Experimental procedure}

\subsection{Materials, Manufacturing and Methods}

From the length variation analysis the desired delamination growth behavior that satisfied the fourth requirement defined in section 2, was found to fall within region IV of Figure 4. Using this plot the desired specimen configuration with $a_{U}$ and $a_{L}$ lengths of $56 \mathrm{~mm}$ and $32 \mathrm{~mm}$ respectively was chosen for the experimental testing.

Specimens were manufactured using IM7/8552 prepreg (Hexcel, UK) stacked in a QI sequence of $(0,-45,90,45)_{2 s} / /\left[(0,-45,90,45)_{2 s}\right]_{2} / /(0,-45,90,45)_{2 s}$ to achieve a nominal thickness of $8 \mathrm{~mm}$, with a $13 \mu \mathrm{m}$ PTFE film placed at the locations marked as $/ /$, which fall between two $0^{\circ}$ plies, preventing any out of plane crack migration. The overall specimen schematic is shown in Figure 8 . In the pinned specimens a region of Z-pins was inserted directly in front of the longest crack.

The pinned specimens were inserted with T300 carbon/BMI pins arranged in a square grid with a spacing of $1.75 \mathrm{~mm}$, generating a nominal $2 \%$ areal density. An example of a manufactured Z-pinned 
specimen is shown in Figure 9, highlighting full penetration of the pins as well as the regularity of the inserted pins.

All the pins in the specimens tested were found to be misaligned approximately $8^{\circ}$ from the nominal vertical axis, which is an artefact of the insertion method used. From Yasaee et. al. [28] this results in a loading mode mixity, $\varphi$ of $99 \%$, regarded to be acceptable in the mode II regime. Six replicates of both the unpinned and pinned configurations with a width of $20 \mathrm{~mm}$, where machined from the same panel.

The specimens were fixed into an ELS test fixture with a nominal 5N/m torque applied on the four individual retaining screws of the clamp. Using a calibrated Instron test machine with a 10kN load cell, the load was applied to the specimen at a displacement rate of $2 \mathrm{~mm} / \mathrm{min}$. The resulting values of Load, $P$, and displacement, $\delta$, were recorded until full propagation of each crack reached the clamped end.

\subsection{Results}

The load-displacement plots of the 6 specimens of the control (unpinned) and 5 specimens of the pinned configuration are shown in Figure 10. A representative load plot of a control sample is presented in Figure 11 alongside the numerical predictions from section 3, showing good agreement for prediction of both load drops. The delamination sequence for the control sample is shown in Figure 12. Both delaminations propagated independently in an unstable manner to the clamped end of the specimen.

A representative load plot of a pinned sample is presented in Figure 13 alongside the results of an unpinned sample. The initiation of the upper delamination occurred at approximately the same load as the control samples, however its unstable propagation was immediately arrested by the Z-pins. With further loading the upper delamination propagated stably to a length of $\sim 72 \mathrm{~mm}$, until the SERR of the lower delamination reached its critical value, initiating an unstable propagation into the Z-pinned region, to the same $\sim 72 \mathrm{~mm}$ length as the upper delamination. With further loading, both delaminations grew simultaneously in a stable manner until reaching the clamped ends.

\subsection{In-situ pin deformation}

To observe in detail the nature of pin deformation during delamination propagation, a pinned sample was polished from the side until a single column of Z-pins was visible. This surface was then treated with a thin layer of transparent epoxy. The specimen was loaded with the same procedure as previously 
described. A snapshot of the loaded specimen at the point where both upper and lower delaminations have propagated towards the clamp is shown in Figure 15. The individual deformation of each row of pins is clearly visible. It is interesting to see that the pins have not fractured but exhibit some pull-out, whilst also showing significant localised bending deformation at the crack plane. This implies that after initiation, the pins are not being loaded in pure mode II due to the small opening observed (Figure 16). The length of the pin that undergoes deformation when loaded in mode II can be measured to be $\sim 0.75 \mathrm{~mm}$, i.e. 6 ply thickness or $\sim 2.67$ times the diameter of a pin, $d_{\text {pin }}$.

An SEM micrograph of a pinned standard ELS specimen tested in mode II is shown in Figure 17. A typical ruptured pin will result in a vacated channel on one fracture surface whilst on the immediate opposite surface the split pin pultruding from its channel is evident.

\section{Discussions}

The experimental procedure investigated here has provided a detailed study of the behaviour of Z-pins subjected to multiple delaminations generated in mode II. As expected the presence of Z-pins were capable of arresting the unstable delamination growth of two independent delaminations. This resulted in stable propagation of both delaminations simultaneously. In-situ examination of the state of the Zpins during the delamination propagation has shown the development of a region of deformation along the Z-pin length $\left(\sim 0.75 \mathrm{~mm}\right.$ long or $\left.\sim 2.7 d_{\text {pin }}\right)$ where the Z-pin is being bent, producing some tensile loading in a transverse dominated regime. In these experiments, similar to any standard mode II fracture toughness tests, the two delaminated segments are unconstrained. This will result in positive traction forces exerted by the Z-pins during bending on the delaminated surfaces, effectively opening the two faces. Although this these tests are described at pure mode II, in the presence of Z-pins some crack opening will be generated, effectively resulting in a high mixed-mode delamination crack. This results in the subsequent pin failure profile described in section 6 with Figure 16 and Figure 17.

The spacing of the delaminations in this investigation were $0.25 \mathrm{~h}(2 \mathrm{~mm})$ from either surface and a $0.5 \mathrm{~h}$ ( $4 \mathrm{~mm}$ ) distance between them. Therefore, if the distance of any delamination is $\sim 1.35 d_{\text {pin }}$ from any other delamination or external surfaces, the pin is expected to resist the delamination independently and thus using measured apparent fracture toughness properties from a single delamination tests will be valid. 
These results show that the fracture profile of the pins is highly dependent on the condition of delamination in the system. The consequence of these differences is important to understand when numerical or analytical models are developed to predict TTR composites with mode II delaminations. It is expected that the energy absorbed by pins loaded in pure mode II will be slightly lower than pins that experience some bending deformation before rupture [28], therefore using pure mode II energy absorption properties to model mode II fractures will produce conservative results.

\section{Conclusions}

An experimental procedure has been presented where controlled multiple mode II delaminations are produced to assess the interaction of TTR pins with two independently propagating delaminations. The test configuration was designed following a comprehensive finite element analysis. A system of cracks was identified to produce the desired delamination propagation behaviour where two delaminations propagated independently from one another. This independence is ideal in that the initiation and propagation can be identified clearly.

The numerical analysis of length variation in a two crack system highlighted the influence these two cracks may have on one another, namely the amplification or shielding that each delamination's SERR would experience relative to the same system with only a single crack. It was found that for a configuration where the SERR amplification of one crack is evident, the SERR of the other crack would be shielded. The combination of the state of the amplification or shielding values of the two cracks highlight a desired region of combined low amplification that corresponds loosely to the region III identified in Figure 4. Crack configurations in this region III correspond to the simultaneous propagation of two cracks in a stable manner. Following the identification of the desired test configuration, experimental tests were carried out to verify the predicted models and to observe the interaction of two independent cracks with TTR pins. Samples with Z-pins were shown to arrest the two independent delaminations, then subsequent stable propagation of the delaminations occurred simultaneously.

A closer look at the nature of deformation of the pins as delamination propagates through the samples allowed confirmation of the pin pull-out and bending failures observed in previous experimental tests. Although the testing procedure was in theory pure mode II, the failure process of the pins generated 
some out of plane opening and thus result in a rupture of the pins which is akin to a high mode mixity loading regime.

These tests provide vital data for validation of numerical modelling tools in development [34]. These tools have been created based on assumptions of single crack growth through a pinned region. With this new data these models can be compared with these results and further developments and improvements can be made if necessary. Future work will need to explore the behaviour of Z-pins to multiple delaminations that have a spacing of less than $1.35 d_{p i n}$ as well as mode I dominated multiple delaminations where the embedded length of a pin will play a major role in the apparent fracture toughness measured. 


\section{References}

[1] Partridge IK, Yasaee M, Allegri G, Lander JK. "Damage-tolerant composite structures by Z-pinning," in Toughening Mechanisms in Composite Materials, Elsevier, 2015, pp. 161-189.

[2] Lander JK. "Designing with z-pins: locally reinforced composite structures," Cranfield University, 2009.

[3] Hashemi S, Kinloch a. J, Williams JG. "The Analysis of Interlaminar Fracture in Uniaxial Fibre-Polymer Composites," Proceedings of the Royal Society A:

Mathematical, Physical and Engineering Sciences, vol. 427, no. 1872, pp. 173199, Jan. 1990.

[4] Reeder JR, Crews Jr. JH. "Mixed-mode bending method for delamination testing," AIAA Journal, vol. 28, no. 7, pp. 1270-1276, 1990.

[5] Kinloch AJ, Wang Y, Williams JG, Yayla P. "Mixed-mode delamination of fibre composite materials," Composites Science and Technology, vol. 47, no. 3, pp. 225-237, 1993.

[6] Wang Y, Williams JG. "Corrections for mode II fracture toughness specimens of composites materials," Composites Science and Technology, vol. 43, no. 3, pp. 251-256, 1992.

[7] Brunner A, Blackman B, Davies P. "A status report on delamination resistance testing of polymer-matrix composites," Engineering Fracture Mechanics, vol. 75, no. 9, pp. 2779-2794, Jun. 2008.

[8] Turon A, Davila C, Camanho PP, Costa J. "An engineering solution for mesh size effects in the simulation of delamination using cohesive zone models," Engineering fracture mechanics, vol. 74, no. 10, pp. 1665-1682, Jul. 2007.

[9] Harper PW, Hallett SR. "A fatigue degradation law for cohesive interface elements - Development and application to composite materials," International Journal of Fatigue, vol. 32, no. 11, pp. 1774-1787, Nov. 2010.

[10] Jiang W, Hallett SR, Green BG, Wisnom MR. “A concise interface constitutive law for analysis of delamination and splitting in composite materials and its application to scaled notched tensile specimens," Online, no. August 2006, pp. 1982-1995, 2007.

[11] Krueger R. "Virtual crack closure technique: History, approach, and applications," Applied Mechanics Reviews, vol. 57, no. 2, p. 109, 2004.

[12] ASTM D5528-01. "Standard Test Method for Mode I Interlaminar Fracture Toughness of Unidirectional Fiber-Reinforced Polymer Matrix Composites," ASTM International, vol. (2007)e2, 2007.

[13] ISO-15024:2001. "Fibre-reinforced plastic composites - determination of mode I interlaminar fracture toughness, GIC, for unidirectionally reinforced materials," International Organisation for Standardisation, vol. 15024, 2001.

[14] ASTM-D7905-14. "Standard Test Method for Determination of the Mode II Interlaminar Fracture Toughness of Unidirectional Fiber-Reinforced Polymer Matrix Composites," ASTM International, 2014.

[15] ISO 15114:2014. "Fibre-reinforced plastic composites — Determination of the 
mode II fracture resistance for unidirectionally reinforced materials using the calibrated end-loaded split (C-ELS) test and an effective crack length approach," International Organisation for Standardisation, vol. 15114. 2014.

[16] ASTM-D6671-06. "Standard Test Method for Mixed Mode I-Mode II Interlaminar Fracture Toughness of Unidirectional Fiber Reinforced Polymer Matrix Composites," ASTM International, 2006.

[17] Cartié DDR, Cox BN, Fleck NA. "Mechanisms of crack bridging by composite and metallic rods," Composites Part A: Applied Science and Manufacturing, vol. 35, no. 11, pp. 1325-1336, Nov. 2004.

[18] Mouritz AP, Koh TM. "Re-evaluation of mode I bridging traction modelling for z-pinned laminates based on experimental analysis," Composites Part B, vol. 56, pp. 797-807, 2014.

[19] Malkin R, Yasaee M, Trask RS, Bond IP. "Bio-inspired laminate design exhibiting pseudo-ductile (graceful) failure during flexural loading," Composites Part A: Applied Science and Manufacturing, vol. 54, pp. 107-116, Nov. 2013.

[20] Zhang B, Allegri G, Yasaee M, Hallett SR, Partridge IK. "On the Delamination Self-Sensing Function of Z-pinned Composite Laminates," Composite Science and Technology, 2016.

[21] Cartie DDR, Troulis M, Partridge IK. "Delamination of Z-pinned carbon fibre reinforced laminates," Composites Science and Technology, vol. 66, pp. 855861, 2006.

[22] Pegorin F, Pingkarawat K, Daynes S, Mouritz AP. "Mode II interlaminar fatigue properties of z-pinned carbon fibre reinforced epoxy composites," Composites Part A: Applied Science and Manufacturing, Aug. 2014.

[23] Rugg KL, Cox BN, Massabò R. "Mixed mode delamination of polymer composite laminates reinforced through the thickness by z-fibers," Composites Part A: applied science and, vol. 33, pp. 177-190, 2002.

[24] M'membe B, Gannon S, Yasaee M, Hallett SR, Partridge IK. "Mode II delamination resistance of composites reinforced with inclined Z-pins," Materials \& Design, vol. 94, pp. 565-572, Jan. 2016.

[25] Davies GAO, Olsson R. "Impact on composite structures," The Aeronautical Journal, vol. 108, no. 1089, pp. 541-563, 2004.

[26] Yasaee M, Bond IP, Trask RS, Greenhalgh ES. "Damage control using discrete thermoplastic film inserts," Composites Part A: Applied Science and Manufacturing, vol. 43, no. 6, pp. 978-989, 2012.

[27] Yasaee M, Killock C, Hartley J, Bond IP. "Control of Compressive Fatigue Delamination Propagation of Impact Damaged Composites Using Discrete Thermoplastic Interleaves," Applied Composite Materials, Oct. 2014.

[28] Yasaee M, Lander J, Allegri G, Hallett S. "Experimental characterisation of mixed mode traction-displacement relationships for a single carbon composite Z-pin," Composites Science and Technology, vol. 94, pp. 123-131, 2014.

[29] Allegri G, Yasaee M, Partridge IK, Hallett SR. "A novel model of delamination bridging via Z-pins in composite laminates," International Journal of Solids and Structures, vol. 51, no. 19-20, pp. 3314-3332, Oct. 2014. 
[30] Zheng S, Sun CT. "Delamination Interaction in Laminated Structures," Engineering Fracture Mechanics, vol. 59, no. 2, pp. 225-240, Jan. 1998.

[31] Larsson P-L. "On multiple delamination buckling and growth in composite plates," International Journal of Solids and Structures, vol. 27, no. 13, pp. 1623-1637, Jan. 1991.

[32] Andrews MG, Massabò R, Cox BN. "Elastic interaction of multiple delaminations in plates subject to cylindrical bending," International Journal of Solids and Structures, vol. 43, no. 5, pp. 855-886, Mar. 2006.

[33] Andrews MG, Massabò R. "Delamination in flat sheet geometries with material imperfections and thickness variations," Composites Part B: Engineering, vol. 39, no. 1, pp. 139-150, Jan. 2008.

[34] Mohamed G, Helenon F, Allegri G, Yasaee M, Hallett SR. "Predicting the through-thickness enhancement of z-pinned composite laminates," in 19th International Conference on Composite Materials, Montreal, Canada, 2013.

[35] OBrien TK, Krueger R. "Analysis of Ninety Degree Flexure Tests for Characterization of Composite Transverse Tensile Strength." National Aeronautics and Space Administration (NASA/TM-2001-211227), 01-Oct2001.

[36] Paris I, Minguet P, Brien TO. "Comparison of delamination characterization for IM7/8552 composite woven and tape laminates," Composite materials: testing and design, vol. 14, 2003.

[37] O'Brien TK, Johnston WM, Toland GJ. "Mode II Interlaminar Fracture Toughness and Fatigue Characterization of a Graphite Epoxy Composite Material," Aug. 2010. 


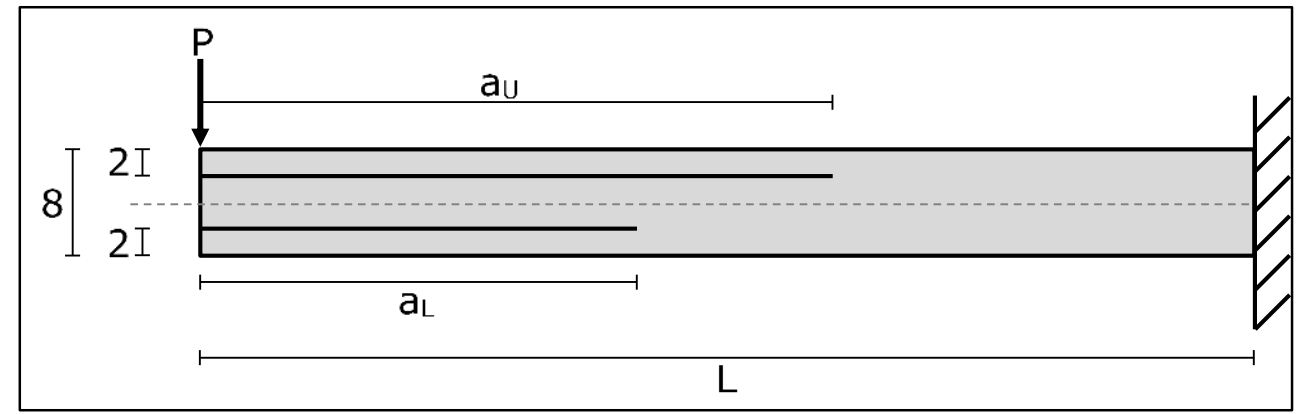

Figure 1 ELS Specimen configuration highlighting the through thickness position of the upper (au) and lower (at) delaminations (dimensions in $\mathbf{m m}$ )

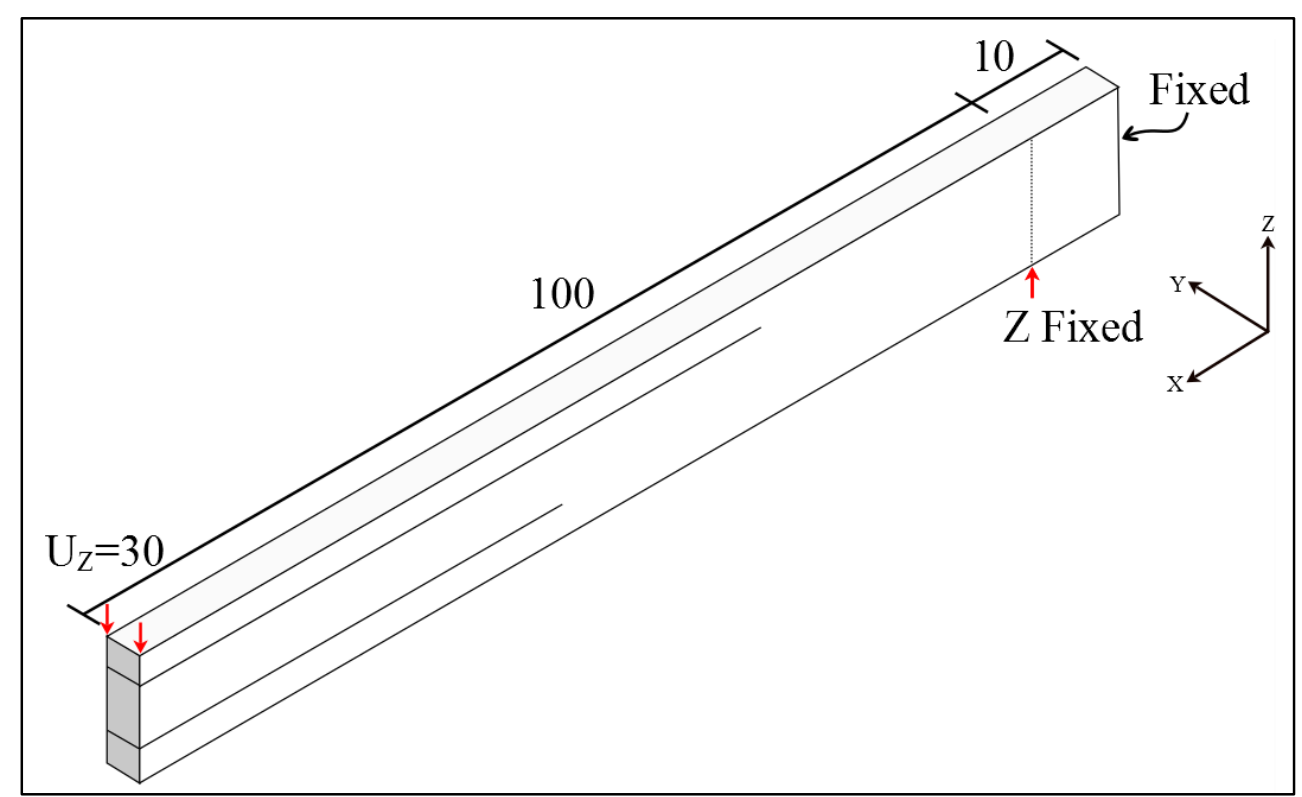

Figure 2 Boundary conditions of the strip model generating plane strain conditions in the $\mathrm{Y}$ axis (dimensions in mm) 


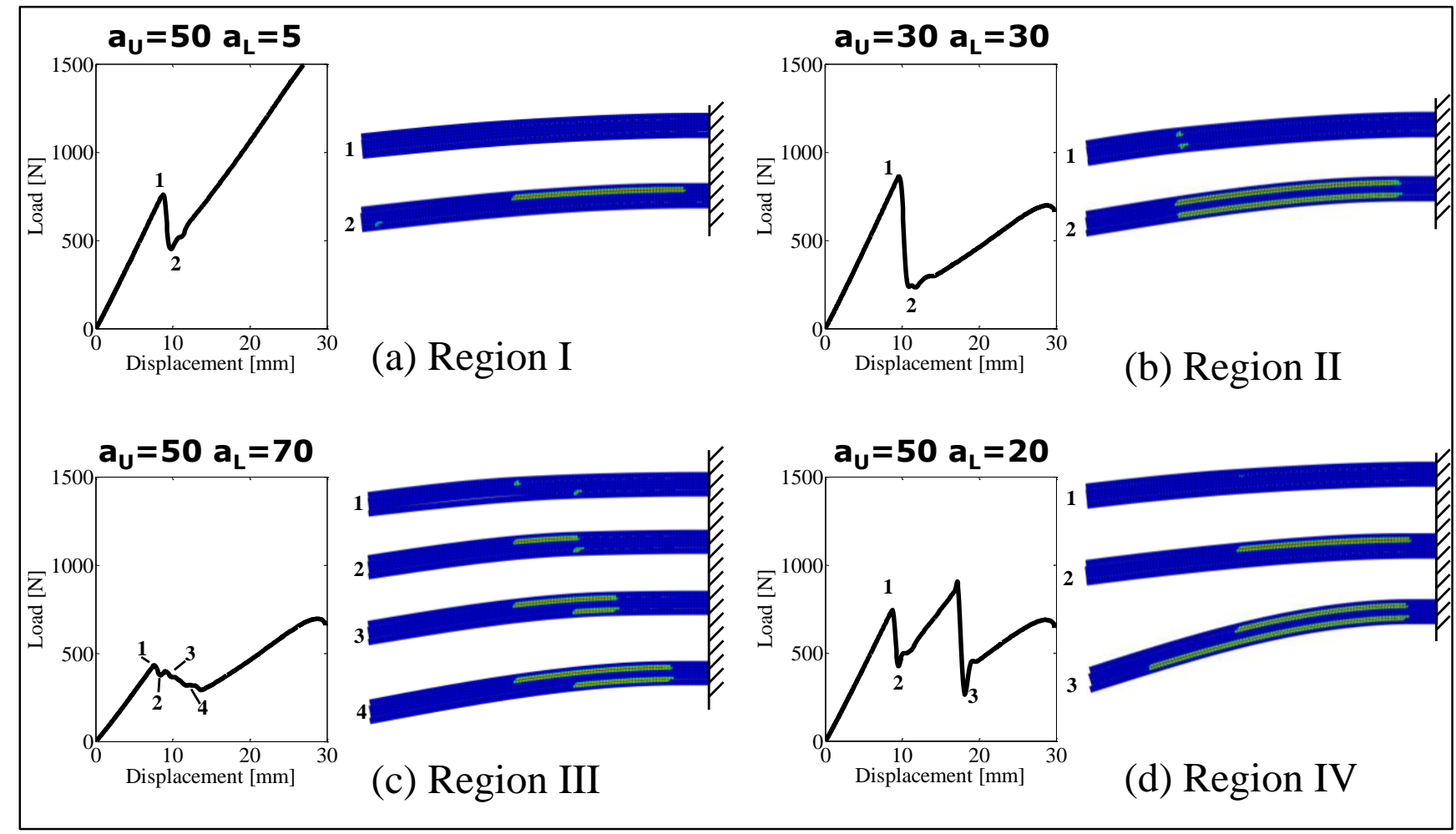

Figure 3 (a) Single unstable delamination, Region I (b) Double simultaneous unstable delaminations, Region II (c) Double simultaneous stable delaminations, Region III (d) Double independent unstable delaminations, Region IV (dimensions in mm)

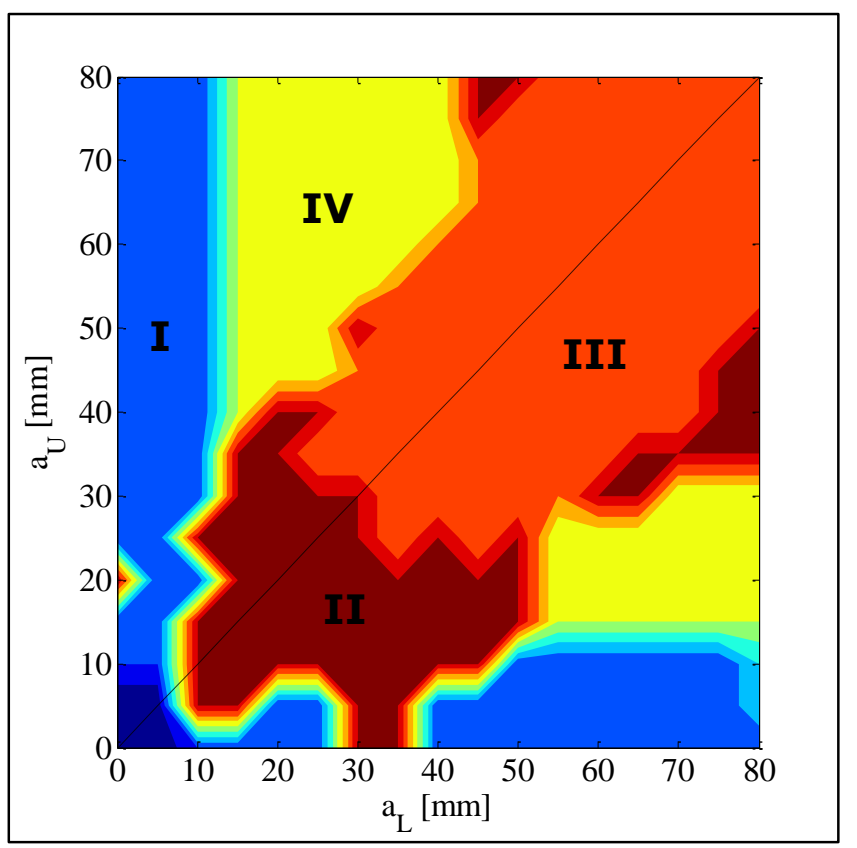

Figure 4 Delamination propagation map highlighting four regions of interest (I) Single unstable delamination, (II) Double simultaneous unstable delaminations, (III) Double simultaneous stable delaminations, (IV) Double independent unstable delaminations 


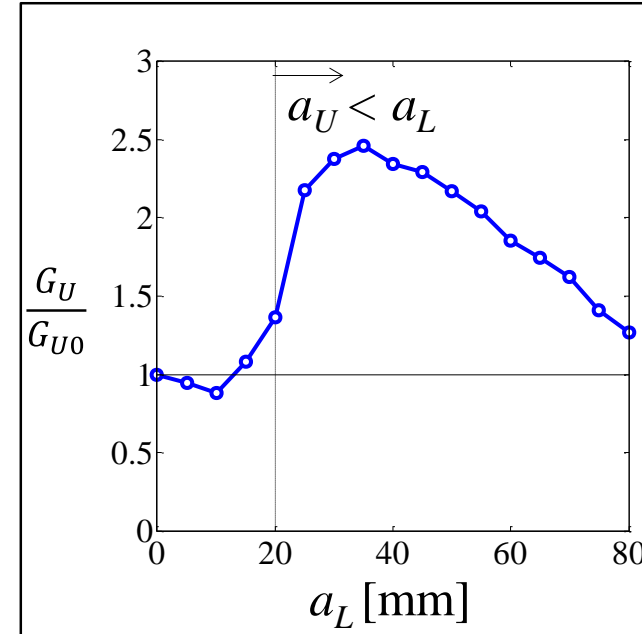

(a)

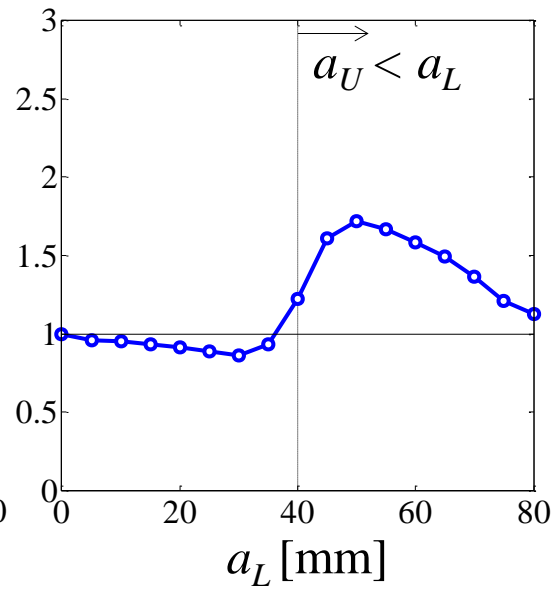

(b)

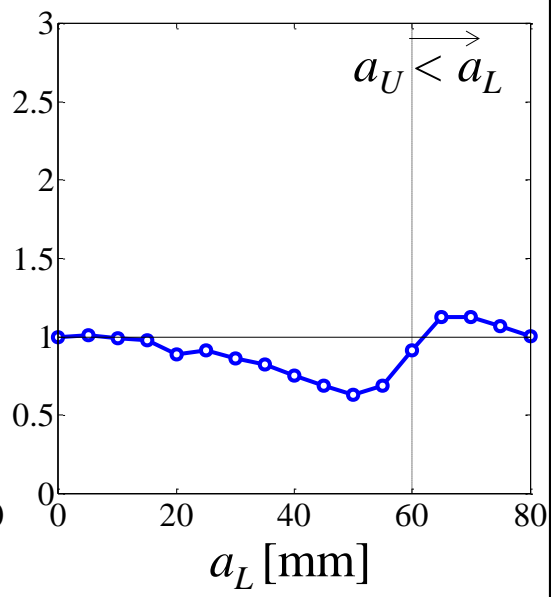

(c)

Figure 5 Example of amplification and shielding of the normalised energy release rate of the upper delamination against increasing lower delamination length when the upper delamination length is fixed at (a) $20 \mathrm{~mm}$ (b) $40 \mathrm{~mm}$ and (c) $60 \mathrm{~mm}$

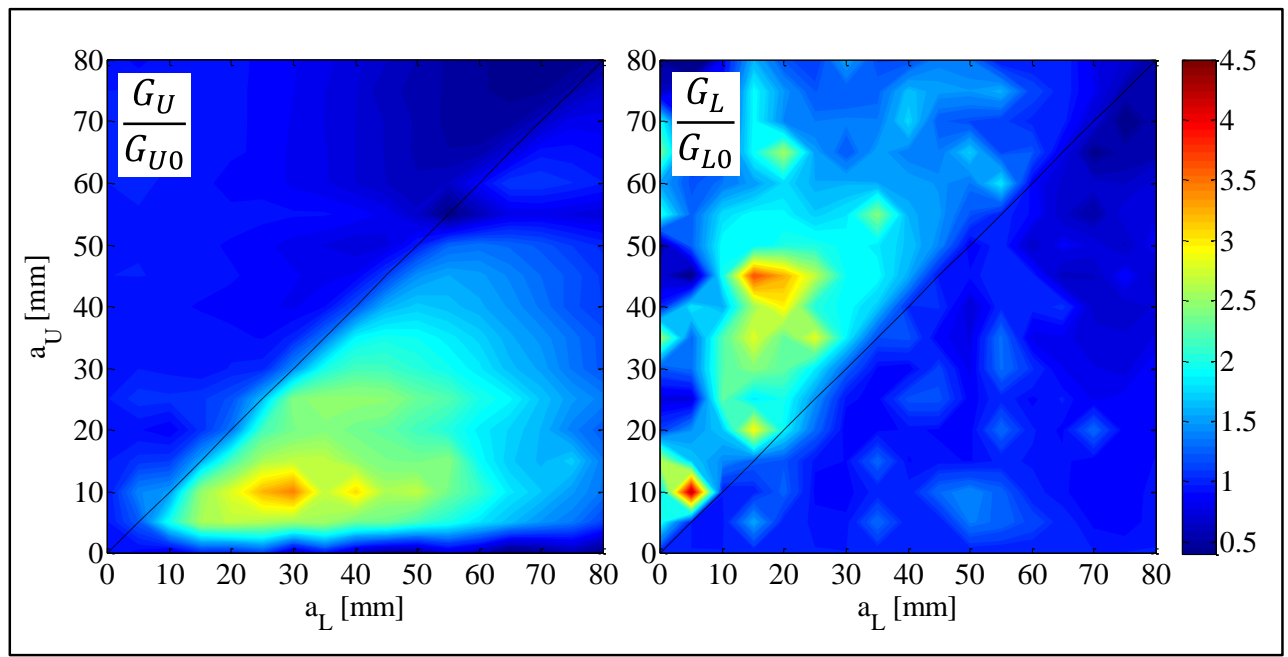

Figure 6 Amplification and shielding map of the upper (left) and lower (right) delaminations 


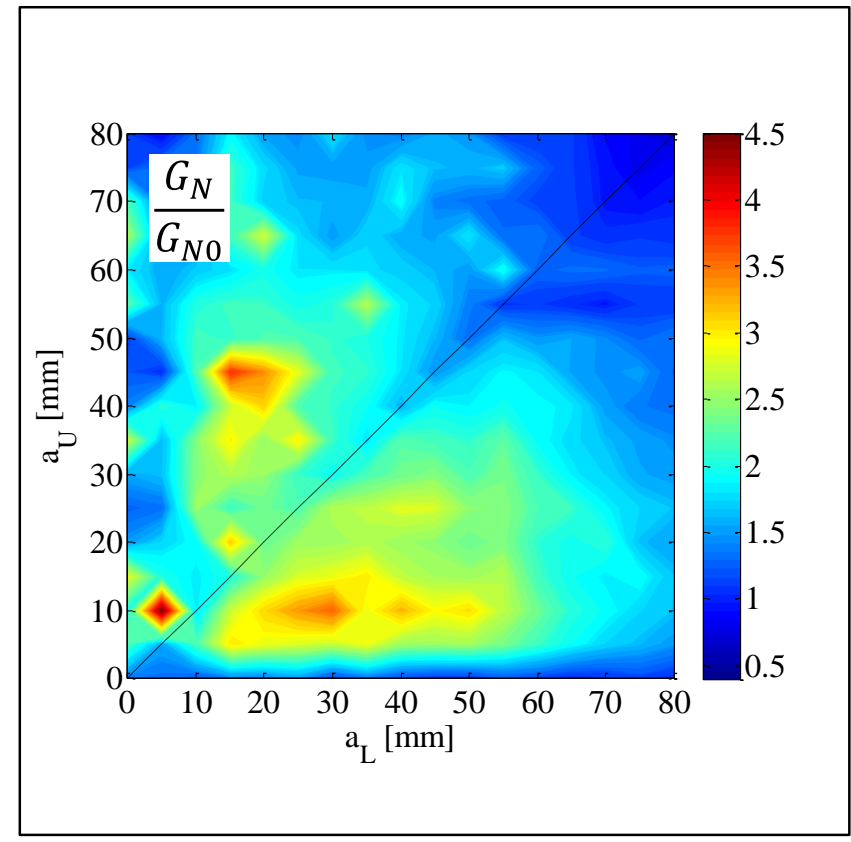

Figure 7 Combined amplification and shielding map

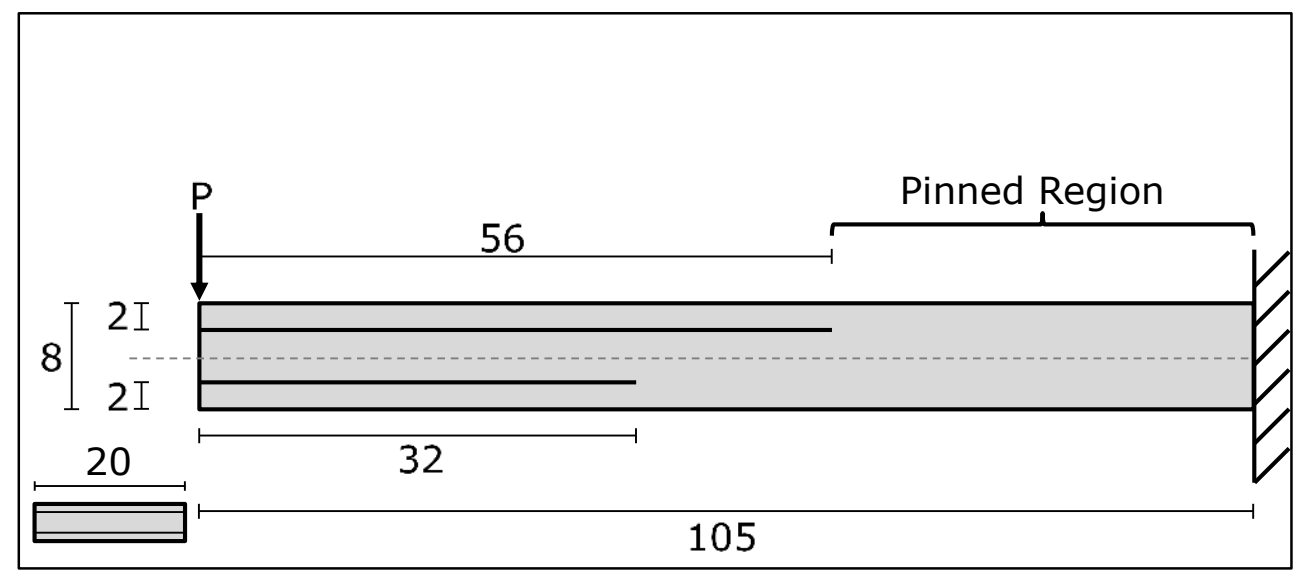

Figure 8 ELS Specimen configuration highlighting length of the upper (au) and lower $\left(a_{L}\right)$ delaminations (dimensions in mm)

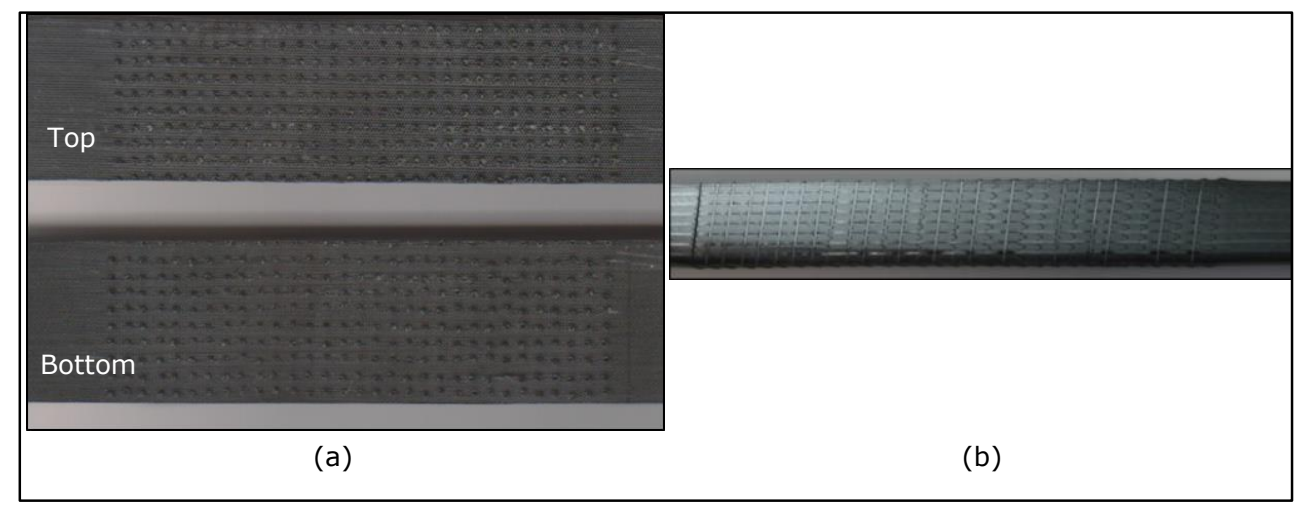

Figure 9 Representative ELS sample with pinned TTR highlighting the high level of regularity (a) Top and bottom view of the sample (b) Polished cross section 


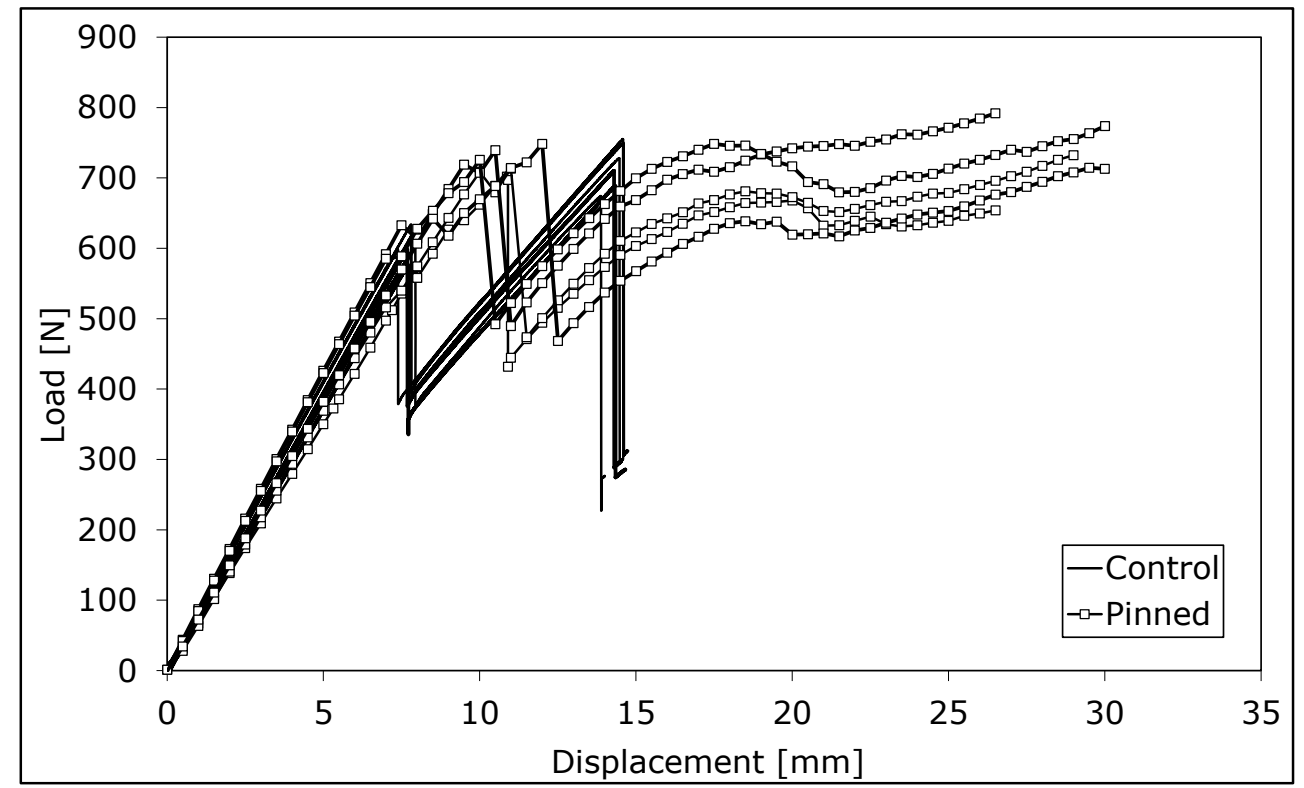

Figure 10 Load-displacement plot of the control and pinned ELS samples highlighting the repeatability of the test procedure

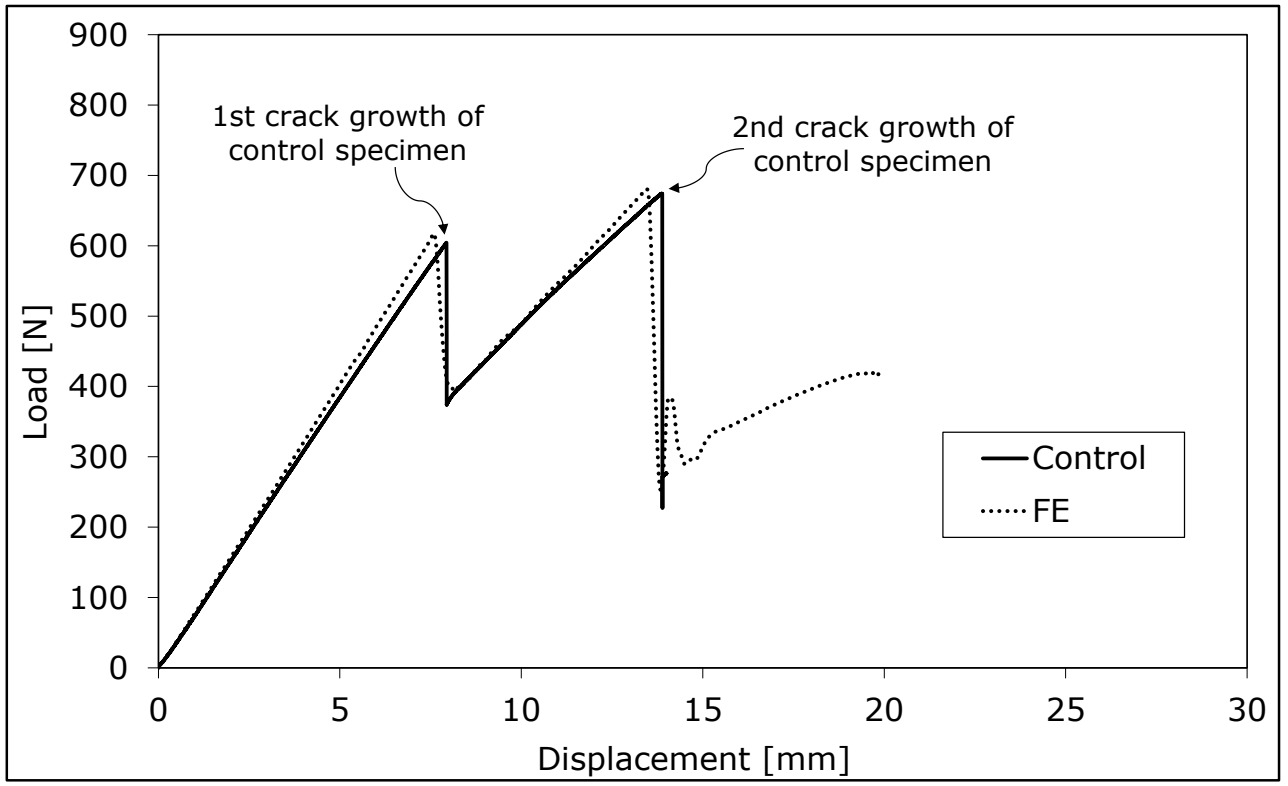

Figure 11 Representative load-displacement plot of the unpinned ELS sample alongside those predicted numerically using FE 


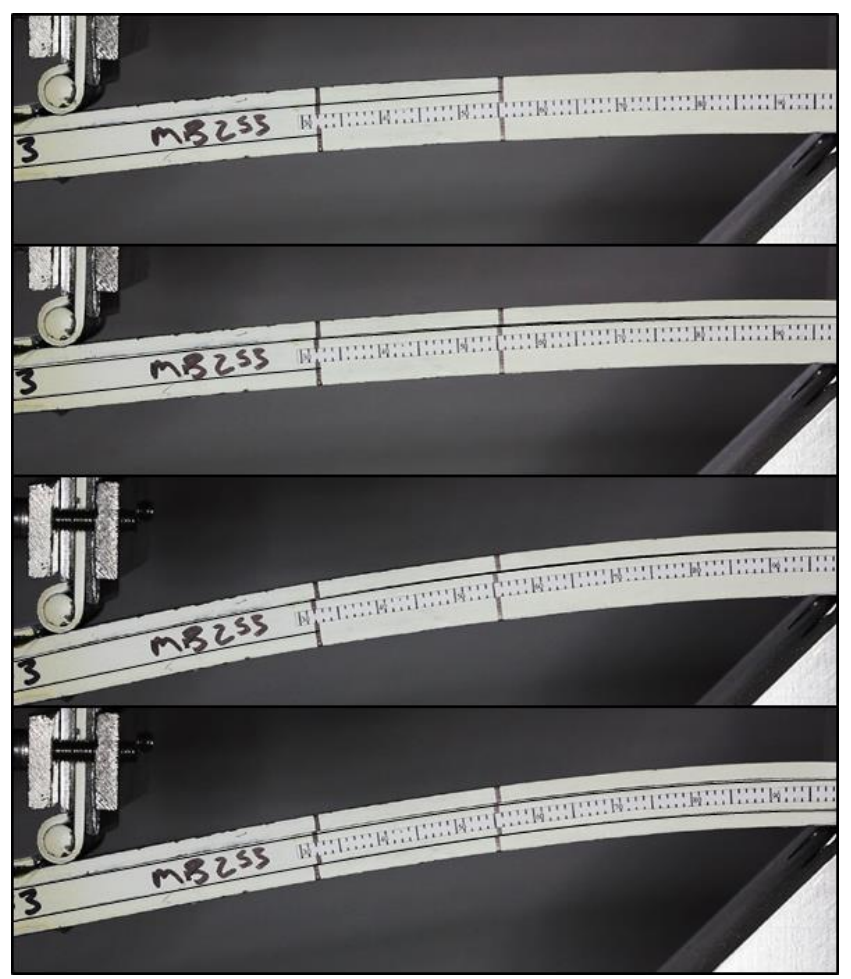

Figure 12 Delamination propagation sequence for control samples (Delaminations highlighted for clarity)

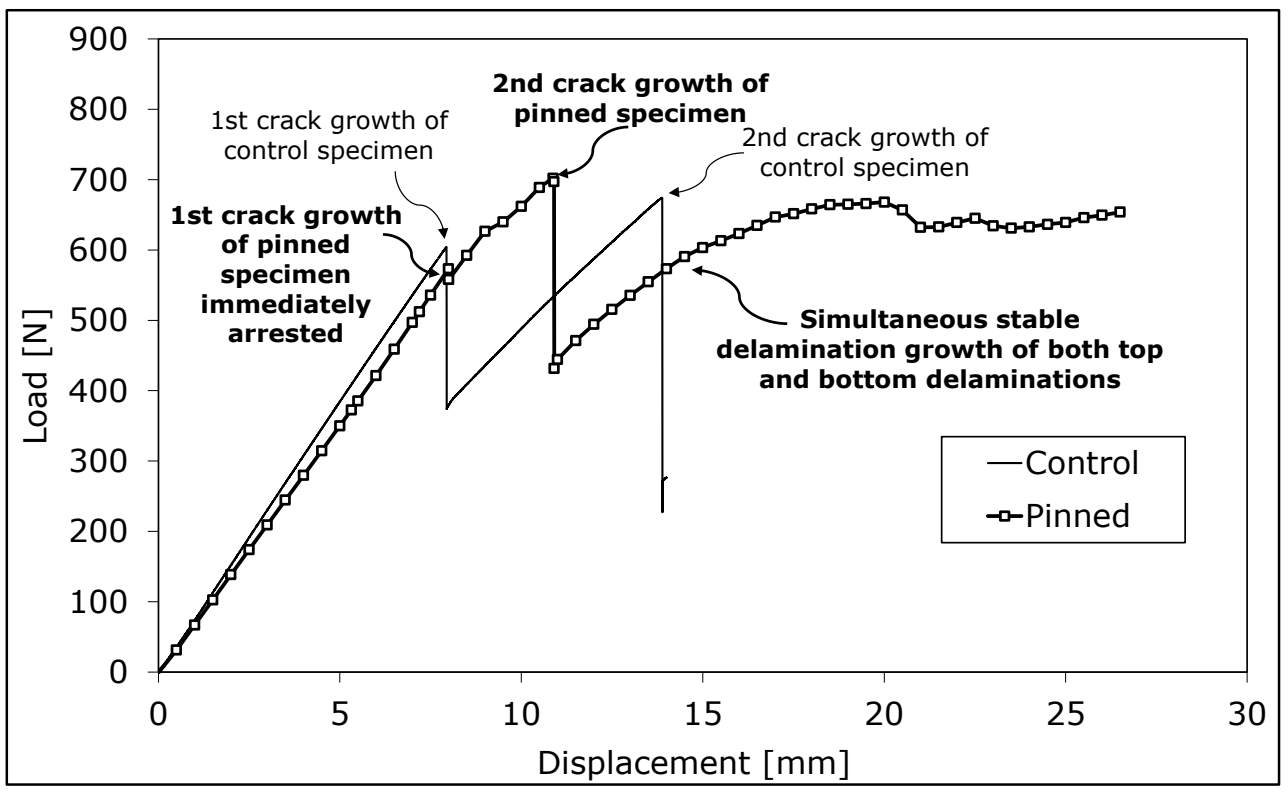

Figure 13 Representative load-displacement plots showing the sequence of delamination growth 


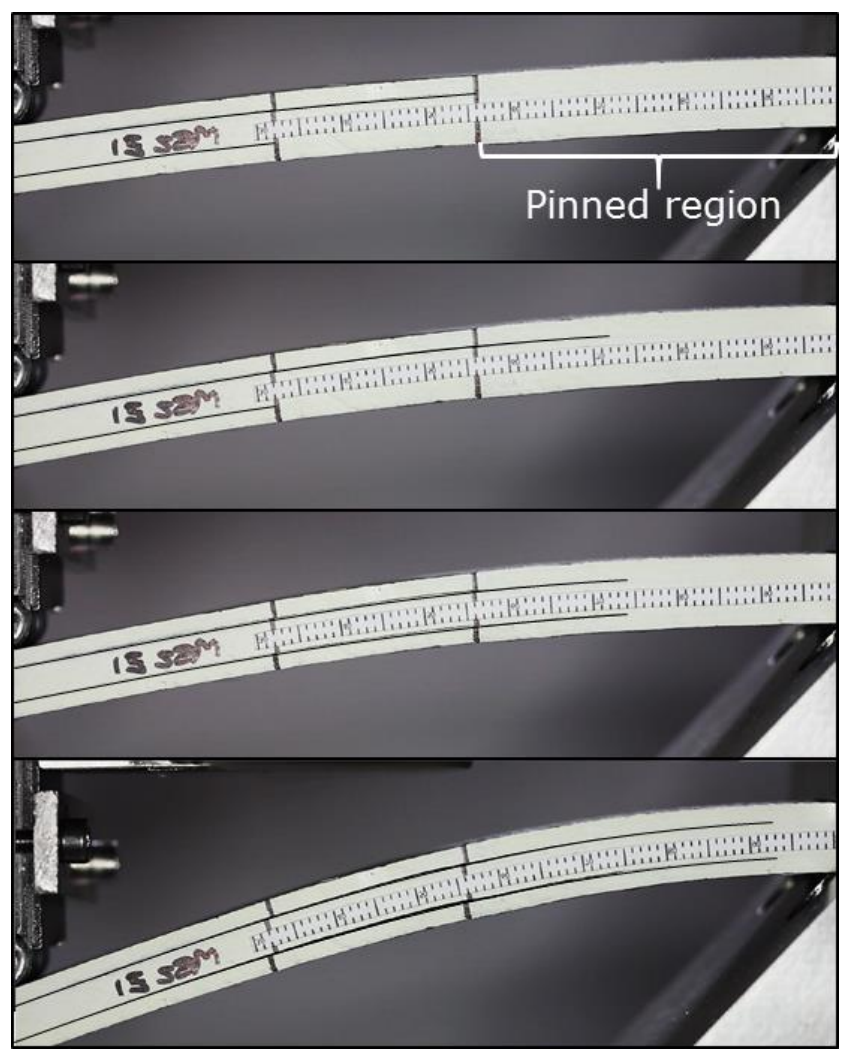

Figure 14 Delamination propagation sequence for pinned samples (Delaminations highlighted for clarity)

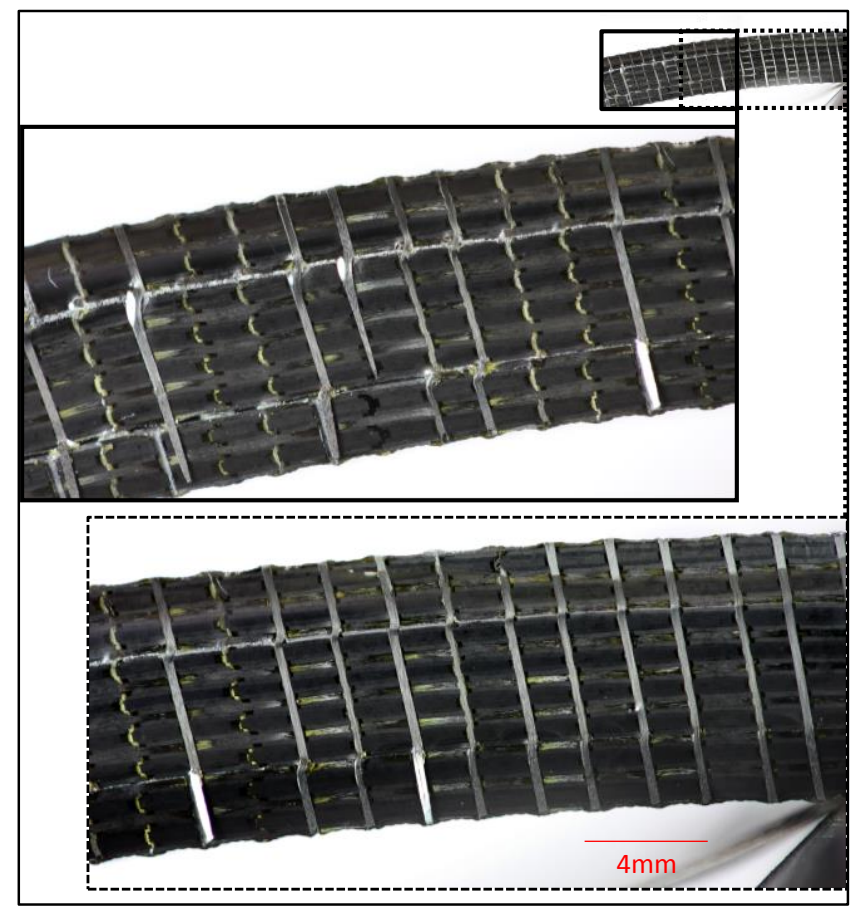

Figure 15 In-situ observation of TTR pins undergoing deformation during delamination growth 


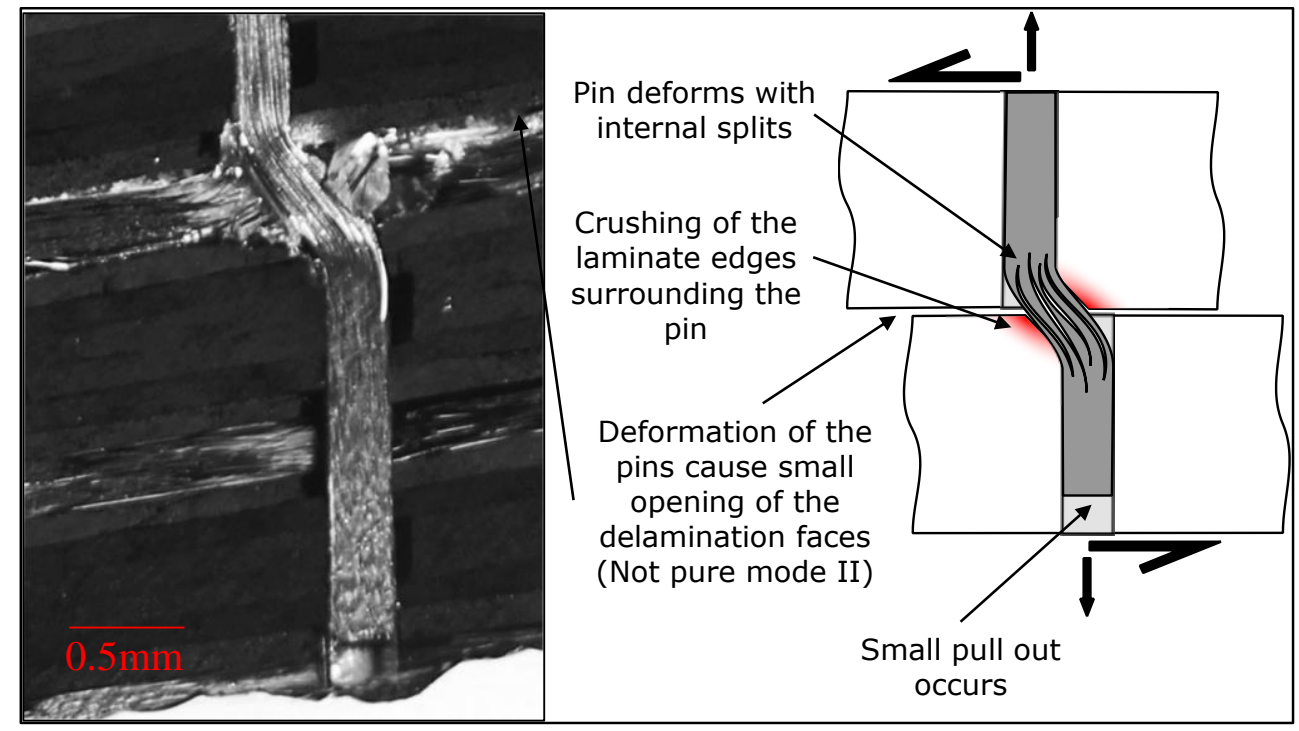

Figure 16 Schematic of the pin deformation behaviour when loaded in an unconstraint mode II loading

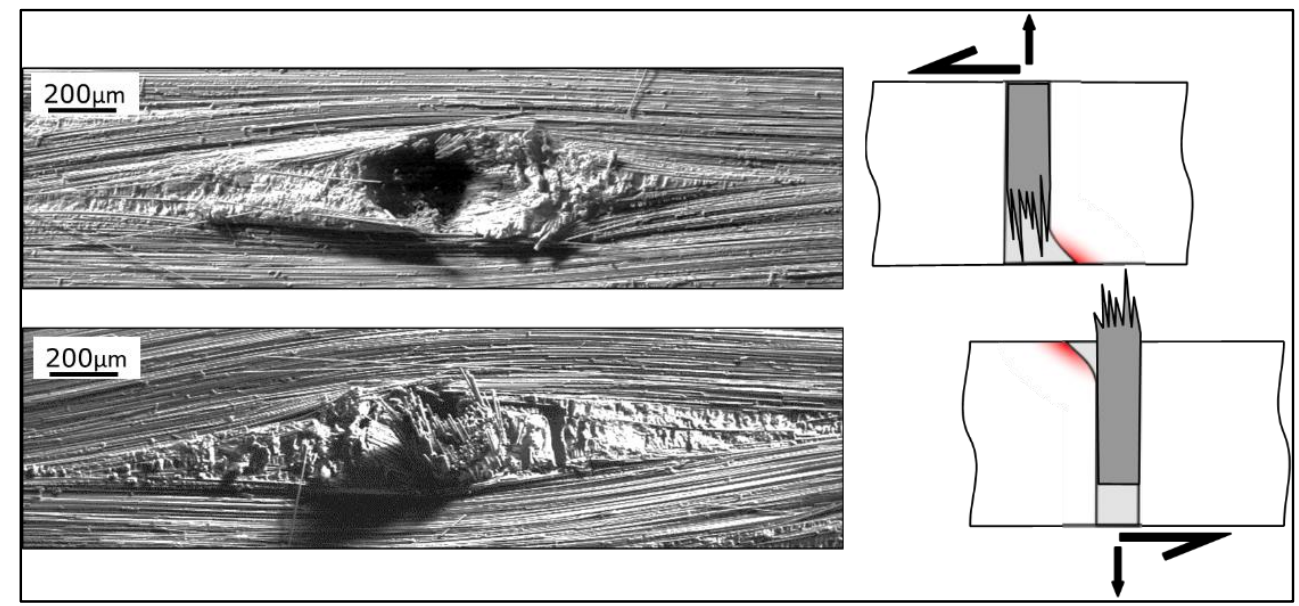

Figure 17 SEM micrographs of carbon composite pin failing in an mode II ELS test 
Table 1 Effective laminate properties of $(0,-45,0,+45)$ QI stacking sequence [35-37]

Effective In-Plane Properties (IM7/8552)

\begin{tabular}{llllll}
$\mathbf{E}_{1}$ & $61.65 \mathrm{GPa}$ & $\mathbf{G}_{12}$ & $23.37 \mathrm{GPa}$ & $\mathbf{v}_{12}$ & 0.3187 \\
$\mathbf{E}$ & $61.65 \mathrm{GPa}$ & $\mathbf{G}_{13}$ & $4.55 \mathrm{GPa}$ & $\mathbf{v}_{13}$ & 0.3161 \\
$\mathbf{E}$ & $13.61 \mathrm{GPa}$ & $\mathbf{G}_{23}$ & $4.55 \mathrm{GPa}$ & $\mathbf{v}_{23}$ & 0.3161 \\
\hline
\end{tabular}

Cohesive Properties $(13 \mu \mathrm{m}$ release film)

$\begin{array}{llll}\mathbf{G}_{\mathbf{I C}} & 211 \mathrm{~J} / \mathrm{m}^{2} & \boldsymbol{\sigma}_{\text {Imax }} \quad 60 \mathrm{MPa}\end{array}$

GIIC $\quad 1050 \mathrm{~J} / \mathrm{m} 2 \quad \boldsymbol{\sigma}_{\text {IImax }} \quad 90 \mathrm{MPa}$ 


\section{Interaction of Z-pins with multiple mode II delaminations in composite laminates}

Yasaee, Mehdi

Springer

M. Yasaee, G. Mohamed and S. R. Hallett. Interaction of Z-pins with multiple mode II

delaminations in composite laminates. Experimental Mechanics, October 2016, Volume 56,

pÿlssue 8, pp1363 1372

http://dx.doi.org/10.1007/s11340-016-0175-9

Downloaded from Cranfield Library Services E-Repository 